\title{
Pharmacological issues in antiretroviral therapy during pregnancy: a clinician's perspective Laurent Mandelbrot
}

\author{
Address: Université Paris 7 - Diderot, APHP-Department of Obstetrics-Gynecology, Hôpital Louis Mourier, Colombes, France \\ from Fifth Dominique Dormont International Conference. Mother-to-child transmitted viral diseases: from transmission to children care \\ Paris, France. 26-28 March 2009 \\ Published: 22 July 2009 \\ Retrovirology 2009, 6(Suppl I):L5 doi:I0.1 I86/I742-4690-6-SI-L5
}

This abstract is available from: http://www.retrovirology.com/content/6/SI/L5

(C) 2009 Mandelbrot; licensee BioMed Central Ltd.

All antiretroviral drugs are eventually used in pregnant women, either as prevention of mother-to-child transmission (PMTCT), or as long-term therapy for the woman's own health. Yet, pregnancy data is lacking for recent drugs. Four types of pharmacologic issues should be addressed:

1) Does $\mathrm{PK} / \mathrm{PD}$ change during pregnancy due to physiological factors (absorption, plasma volume, plasma proteins such as albumin and alpha acid glycoprotein, cytochrome induction), and can this lead to reduced efficacy? Plasma concentrations are decreased during the $3 \mathrm{~d}$ trimester for several protease inhibitors (PIs). This has led to 2 strategies, increasing the dose or performing therapeutic drug monitoring, however there is debate as to whether such measures are useful when maternal viral replication is under control.

2) Does the drug penetrate into the genital tract, and does this play a role in prevention of transmission? Preliminary data shows that the penetration of drugs into the genital tract differs widely between drugs, and is very poor for some PIs. Since one of the mechanisms of MTCT is vertical transmission, and since viral replication in the vaginal compartment can persist despite undetectable plasma HIV RNA, there is concern as to whether low intravaginal drug levels may lead to an increased transmission risk, especially during vaginal delivery.

3) Does it cross the placenta, and what are the potential benefits and risks of fetal exposure? For the fetus, placental transfer may either be harmful because of toxicity or protective (PrEP). Most NRTIs diffuse across the placenta, the fusion inhibitor enfuvirtide does not, and there are wide differences between the various PIs. A number of factors are known to limit drug transfer (some of which are unique to the placenta), including molecular size (impermeable $>1000 \mathrm{kDa}$ ), low lipid solubility of drug, pKa, low protein binding, low placental blood flow, placental fixation, placental metabolism, fetal acidosis. Efflux pumps such as P-glycoprotein (MDR1) present in the trophoblast are involved in protecting the fetus from xenobiotics in the maternal compartment. They play an important role in decreasing transfer of PIs to the fetus. Genetic polymorphisms may account for inter-individual differences. Thus, placental transfer cannot be entirely predicted from the physico-chemical properties of the drug, nor from its transfer across other barriers. Several methods can be used to determine placental transfer: clinical data (sampling at delivery for cord blood/maternal blood ratio), animal models, in vitro models, ie. cell cultures, placental tissue slices, and the ex vivo human perfused cotyledon. The perfused cotyledon model, which determines a clearance index, is generally predictive. Clinical data must be interpreted cautiously because only a single paired cord/maternal sample is available, and the ratio can change according to timing of delivery after the last administration of the drug. Population pharmacokinetics allows for more accurate modeling with this type of data.

4) Is it metabolized by fetus, and how does this influence its toxicities? Metabolism differs from adults due to immaturity of fetal CYP3A (CYP3A7), as well as excretion in the urine and gut. Little is known about the clearance of drugs and metabolites from the fetus back through the placenta. Thus, consequences on the fetus cannot be predicted simply from placental transfer.

In conclusion, placental transfer differs between ARVs and is influenced by many factors. Poor placental transfer may be an advantage, in order to avoid toxicity to the fetus, or a disadvantage for PrEP. In order to help clinicians and 
patients to choose the optimal regimen, placental transfer should be evaluated as part of the licensing procedure for medications.

Publish with Bio Med Central and every scientist can read your work free of charge

"BioMed Central will be the most significant development for disseminating the results of biomedical research in our lifetime. " Sir Paul Nurse, Cancer Research UK

Your research papers will be:

- available free of charge to the entire biomedical community

- peer reviewed and published immediately upon acceptance

- cited in PubMed and archived on PubMed Central

- yours - you keep the copyright 